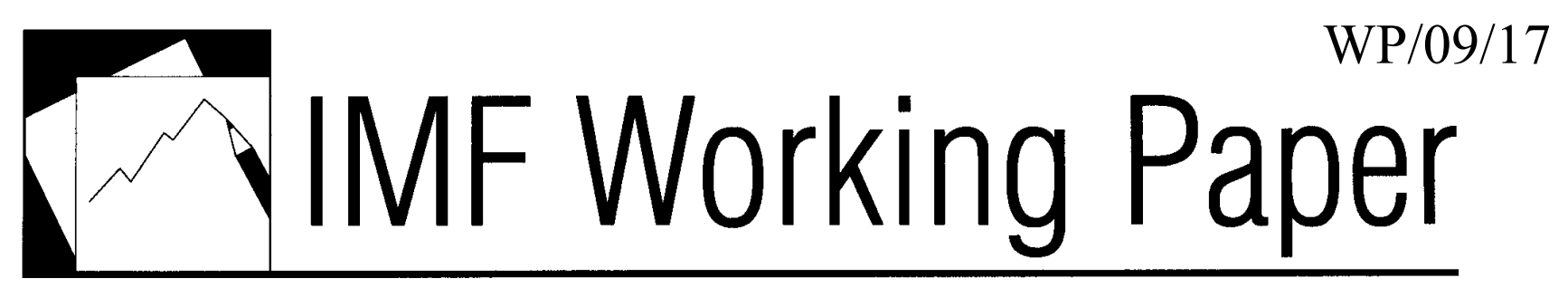

\title{
Does Global Liquidity Matter for Monetary Policy in the Euro Area?
}

\author{
Helge Berger and Thomas Harjes
}





\title{
IMF Working Paper
}

European Department

\section{Does Global Liquidity Matter for Monetary Policy in the Euro Area?}

\author{
Prepared by Helge Berger and Thomas Harjes ${ }^{1}$
}

Authorized for distribution by Luc Everaert

January 2009

\begin{abstract}
This Working Paper should not be reported as representing the views of the IMF. The views expressed in this Working Paper are those of the author(s) and do not necessarily represent those of the IMF or IMF policy. Working Papers describe research in progress by the author(s) and are published to elicit comments and to further debate.
\end{abstract}

Global excess liquidity is sometimes believed to limit sovereign monetary policy even in large economies, including the euro area. There is much discussion about what constitutes global excess liquidity and our approach adjusts liquidity for longer-term interest rate and output effects. We find that especially excess liquidity in the U.S. leads developments in euro area liquidity. U.S. excess liquidity also enters consistently positive as a determinant of euro area inflation. There is some evidence that this result may be related to a weakening of the effectiveness of monetary policy in the euro area during times of excessive U.S. liquidity.

JEL Classification Numbers: C22, C53, E31, E52, F42

Authors’ E-Mail Address: helge.berger@,fu-berlin.de, tharjes@,imf.org

Keywords:

Global excess liquidity, euro area, inflation, monetary policy, interest rate channel, forecasting accuracy

\footnotetext{
${ }^{1}$ We thank participants of the ECB workshop on the external dimension of monetary analysis held in Frankfurt on December 2007 and an IMF seminar, and Jorg Decressin in particular, for helpful comments and suggestions. Berger thanks the IMF's European Department for its hospitality. The views expressed herein are those of the authors and should not be attributed to the IMF, its Executive Board, or its management.
} 


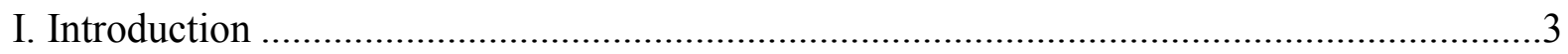

II. How to Identify Movements in Liquidity Relevant for Monetary Policy? .........................5

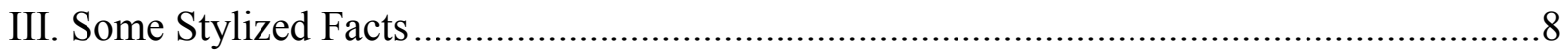

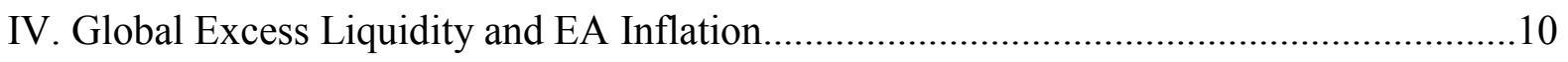

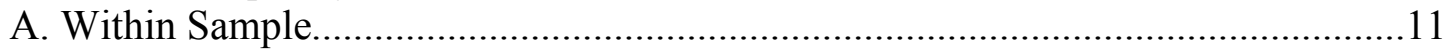

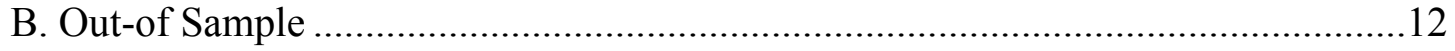

V. A Glimpse at the Link between Global Liquidity and Monetary Policy Effectiveness......15

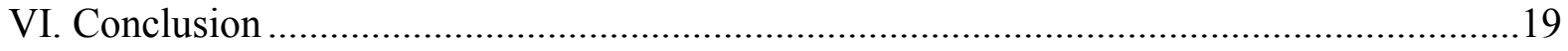

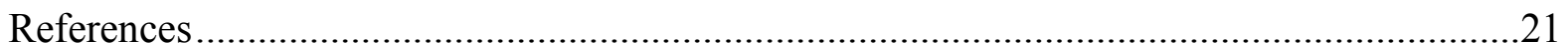

Table 1. The Impact of EA, US, and JP Excess Liquidity on Future Inflation.......................11

Figures

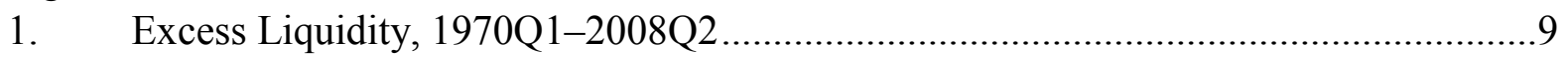

2. Dynamic Correlation Coefficients of Excess Liquidity......................................... 9

3. RMSEs for Alternative Models of Euro Area Inflation for the Forecasting Period

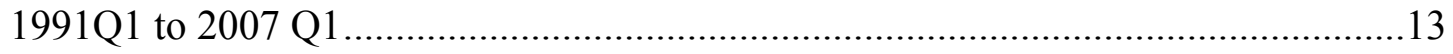

4. Results from an Uncionditioanl VAR for th Euro Area 1991Q1 to 2007Q1..............16

5. Results from a VAR for the Euro Area 1991Q1 to 2007Q1, Conditional on the US Excess Liquidity Regime ............................................................................. 18

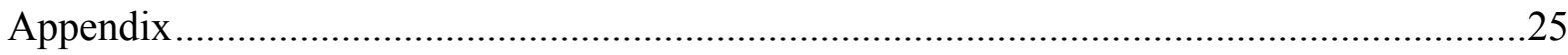




\section{INTRODUCTION}

There has been a surge in liquidity around the world in recent years. Exceptionally low interest rates, in particular in the three largest economies with a common currency, the U.S., the euro area, and Japan, as well as financial globalization, together with financial innovation and increased market participation, have led to monetary and financial conditions which were, at least until August 2007, characterized by abundant liquidity. ${ }^{2}$ Low (long-term) interest rates not only mirrored a very accommodative monetary policy stance in these economies, which ended in the United States and the euro area in 2006 and 2007, respectively, but probably also reflect the impact of global savings-investment imbalances that built over the past years.

With the surge in global liquidity, renewed interest has surfaced in the link between global liquidity and inflation. Any such analysis requires a relevant concept of liquidity. Global liquidity is often defined as a measure of the monetary policy stance that determines the supply of cash, by definition the most liquid asset. An alternative concept is that of global market liquidity. The degree of market liquidity is higher the lower the expected costs incurred by converting an asset, at any point in time, into cash. Obviously, these concepts are related; an accommodative monetary policy stance raises the supply of highly liquid assets and should lower the expected costs of converting a less liquid asset into cash. Nevertheless, for the analysis of the relationship between global liquidity and inflation, the "macro" liquidity concept appears to be the more relevant one.

There are various channels through which global excess liquidity could have an impact on euro area inflation. In a standard New Keynesian dynamic general equilibrium model with sticky prices, monetary expansion abroad would appreciate the euro area exchange rate and temporarily raise foreign demand for euro area goods. The net-effect on euro area inflation could very well be positive, for instance if euro-prices of imported goods were sticky enough to limit the effect on imported goods prices, perhaps due to prevailing pricing-to-market strategies. ${ }^{3}$ A second channel—admittedly perhaps less relevant for the euro area-could be monetary policy. For instance, a central bank might react to more expansionary foreign monetary conditions with lower interest rates at home for reasons of external competitiveness.

Finally, there could be liquidity arbitrage. Ample global liquidity may have a direct effect on regional monetary conditions through a "search for yield", with possible repercussions on risk aversion and/or perceived risk of specific asset classes. For instance, so called "carry trades",

\footnotetext{
${ }^{2}$ For a discussion of concepts, recent developments of global liquidity indicators and its implications for monetary policy, see IMF (2007), or the speeches by ECB Excecutive Board Member L. Bini-Smaghi (2007), or U.S. Federal Reserve Governor K. Warsh (2007).

${ }^{3}$ In the standard New Keynesian model, movements in liquidity or money are often ignored in favor of a more streamlined "cashless" model focused on interest rates alone (e.g., Woodford 2003, 2007). This is equivalent to models including money, unless real balance effects, non-separabilities, or money stock adjustment costs are assumed to be important (e.g., Andrés et al. 2007). Quantity theorist argue that even in a "cashless" economy global money could have a specific role in the transmission mechanism as a proxy for a whole spectrum of other rates of return, in particular, if asset prices had an essential role in the transmission mechanism of monetary policy—see, among others, Nelson (2003) and Svensson (2003) for a discussion.
} 
where investors borrow in national currencies with low interest rates and invest in higher yielding currencies while mostly disregarding exchange rate risk (and other similarly structured investment strategies) are a good example of how liquidity conditions elsewhere directly affect a region's liquidity conditions. As a result, regional monetary policy might find it more difficult to influence financing conditions through the interest rate channel, in particular toward the longer end of the yield curve.

Several studies recently investigated the relationship between global liquidity and inflation, mostly using simple aggregates of national monetary measures. Sousa and Zaghini (2004) analyze the international transmission of monetary shocks with a special focus on the effects of global liquidity, measured as a simple sum of the monetary aggregates of the euro area, the United States, the United Kingdom, Japan and Canada on the euro area. They find that a positive shock to extra-euro area liquidity leads to permanent increases in the euro area M3 aggregate and the price level. Rüffer and Stracca (2006) conclude that excess liquidity is a useful indicator of inflationary pressure at a global level. They also find evidence of a significant spillover of global liquidity to the euro area economy and, to a lesser extent, to Japan. However, the impact of global excess liquidity on the US economy is found to be smaller and goes in the opposite direction. D'Agostino and Surico (2007) use a measure of global liquidity, defined as the simple mean of the growth rates of broad money in the G7 economies, to produce forecasts of US inflation that are significantly more accurate than the forecasts based on US money growth and an autoregressive model. The marginal predictive power of global liquidity is strongest at three years horizons.

A possible shortcoming of this evolving literature may be the definition of global liquidity. The studies fail to adjust global liquidity for the long-term movements in opportunity-costs of holding money and output effects, although past research on the relationship between inflation and money in large industrial countries has highlighted the fact that simple measures of money growth may not always serve as a reliable guide to future inflation. Orphanides and Porter (2000) emphasize that, in particular over shorter horizons, interest-rate induced variations in the output-velocity of money complicate the link between standard monetary aggregates and prices. Reynard (2007) shows that adjusting for the phase in the relationship-i.e., for the lag from money growth to inflation - and, for long-term movements in output and opportunity costs are crucial steps in establishing a relationship between money and inflation in the U.S., euro area, and Switzerland. Also, some of the studies analyzing the impact of global liquidity on regional or national inflation include the regional or national component of money in their global measure - which may make it more difficult to identify global liquidity effects.

In the present paper, we take a closer look at the effect of global liquidity on euro area inflation. Our approach carefully adjusts liquidity for longer-term interest rate and output effects and focuses on U.S. and Japanese liquidity as relevant proxies for global developments. ${ }^{4}$ A number of results emerge. First, we find that excess liquidity (defined as levels of M2 in excess of

\footnotetext{
${ }^{4}$ We restrict our analysis to the three largest economies with a common currency, as these account for the major part of global liquidity. While several emerging economies are certainly gaining influence, there national currencies are often not fully convertible and a host of capital account restrictions remain in place which makes it difficult to interpret their national monetary aggregates in a global context.
} 
money demand implied by longer-run interest rates and output developments) in the U.S. and Japan is correlated with excess liquidity in the euro area, and that these global excess liquidity measures tend to lead developments in euro area. Both results are particularly strong for the U.S. and during the post-1990 period.

Second, we show that U.S. excess liquidity has a consistent positive impact on future rates of inflation in the euro area at horizons up to 12 quarters both within- and out-of-sample. More specifically, U.S. excess liquidity enters consistently positive as a determinant of euro area inflation and is shown to be Granger-causal (i.e., having a positive influence on forecasting accuracy) for euro area inflation in a systematic out-of-sample forecasting exercise. In contrast, the marginal contribution of Japanese and euro area excess liquidity to the within-sample explanation of euro inflation is more limited and their impact on inflation forecasting accuracy is small or even negative.

These findings suggest that global liquidity conditions, proxied by U.S. liquidity, may matter for inflation but national money only plays a minor role - and the question is why. At a technical level, the greater influence of global excess liquidity on euro area inflation seems to stem from the fact that global measures move less idiosyncratically than the domestic ones. Economically, possible explanations include indirect effects of global liquidity working through a reaction of euro area liquidity to global developments, with repercussion for inflation along quantitytheoretical lines. There could also be direct effects operating through changing international asset and commodity prices (ECB, 2008). Yet others have pointed out that monetary policy might loose its effectiveness due to financial globalization (Mishkin, 2008). For instance, in the presence of a credit-channel mechanism, ample global liquidity might mitigate the domestic effects of monetary policy.

To shed some further light on this issue, we use a simple VAR framework for the euro area and ask whether varying global liquidity regimes impact the monetary transmission mechanism in the euro area. The results, while suffering from data limitations, indicate that the impact of euro area interest rate shocks may have been muted in period of positive U.S. (or global) excess liquidity, which could be interpreted as evidence along the lines of a credit-channel mechanism.

The structure of the paper is as follows. Sections 2 and 3 discuss our definition of excess liquidity and develop some stylized facts on its empirical behavior for the case of the U.S., Japan, and the euro area. Section 4 analyzes the within- and out-of-sample link between global and euro area excess liquidity and euro are inflation, while Section 5 takes a brief look at the impact of excess liquidity regimes on the interest rate channel in the euro area. Section 6 concludes.

\section{How to Identify Movements in LiQuidity Relevant for Monetary Policy?}

With current New Keynesian models (NKM) providing little guidance with regard to the role liquidity may play for monetary policy (see Woodford 2007), some economists and central bank practitioners have turned to the so-called P-star (or $\mathrm{P}^{*}$ ) model, which makes pragmatic use of 
the quantity theory of money to predict future price developments. ${ }^{5}$ The $\mathrm{P} *$ model, while lacking the theoretical microfoundations of the NKM (Gerlach and Svensson, 2003), has been found to do well in explaining inflation trends in the euro area data in particular in the medium to longer run (Deutsche Bundesbank, 2005). ${ }^{6}$ Also Fischer et al. (2008) report that the ECB has implemented $\mathrm{P}^{*}$ models for internal use. ${ }^{7}$

Starting point of the $\mathrm{P}^{*}$ model is the assumption that deviations of the (log of the) actual price level, $p$, from the equilibrium price level, $p^{*}$, the so-called price gap, can be used to predict future price adjustments and, thus, inflation. ${ }^{8}$ As Svensson (2000) illustrates, the price gap, $p^{*}$ $p$, can be expressed as the real monetary gap or excess liquidity, $\widetilde{m}_{t}$, defined as the difference (in logs) between the real money stock, $m_{t}^{\text {real }} \equiv m_{t}-p_{t}$ and its equilibrium level, $m_{t}^{\text {real }}{ }^{*} \equiv m_{t}-p_{t}^{*}$ :

$$
\tilde{m}_{t} \equiv m_{t}^{\text {real }}-m_{t}^{\text {real* }}=p_{t}^{*}-p_{t} \text {. }
$$

Gerlach and Svensson (2003) note that this version of the $\mathrm{P}^{*}$ model is particularly useful for a discussion of the predictive power of monetary aggregates regarding inflation. The question remains, of course, how to implement the concept.

To that end, the $\mathrm{P}^{*}$ model defines $p^{*}$ as the equilibrium level of prices supported by the current quantity of money in circulation, $m$, given potential output, $y^{*}$, and equilibrium velocity, $v^{*}$ (all in $\log s)$

$$
p_{t}^{*} \equiv m_{t}+v_{t}^{*}-y_{t}^{*}
$$

This implies that the equilibrium real money stock is $m_{t}^{\text {real }}{ }^{*}=-v_{t}^{*}+y_{t}^{*}$ and that excess liquidity can be expressed as $\tilde{m}_{t}=m_{t}^{\text {real }}+v_{t}^{*}-y_{t}^{*}$.

To complete the framework, we have to define equilibrium velocity. Following Orphanides and Porter (2000) and Reynard (2007), $v^{*}$ can be modeled as

\footnotetext{
${ }^{5}$ See, inter alia, Hallman et al. (1991), von Hagen (1995), Tödter and Reimers (1997), Neumann (1997), Orphanides and Porter (2000), or Masuch et al. (2001).

${ }^{6}$ André et al. (2007) show that, in principle, a link between inflation and the monetary gap can be more rigorously derived in a standard NKM along the lines of Woodford (2003) - provided that the model is amended to include non-separability across real balances and consumption in the household utility function. However, among other things, such a model would demand that inflation depends on expected real marginal costs, a feature not captured in the traditional $\mathrm{P} *$ model.

${ }^{7}$ One reason seems to have been the rising prominence of simpler bivariate inflation forecasting models within the ECB (Fischer et al 2006).

${ }^{8}$ The definition of the price gap is arbitrary. For instance, Svensson (2000) uses $p-p^{*}$.
} 


$$
v_{t}^{*}=c+\beta i_{t}^{*},
$$

where $i^{*}$ is the equilibrium short-term interest rate proxying the opportunity costs of money holdings and $-\beta$ is the interest rate semi-elasticity of real money in a demand equation that includes a constant $c$ and where a unitary income elasticity has been imposed. ${ }^{9}$ Thus, equation (1) takes the final form

$$
\tilde{m}_{t}=c+m_{t}^{\text {real }}+\beta i_{t}^{*}-y_{t}^{*}
$$

which is similar to Reynard (2007). ${ }^{10}$

This measure of excess liquidity can be taken to the data. Our starting point is the monetary aggregate M2, which has a number of advantages. ${ }^{11}$ Other than more broadly defined liquidity measures, M2 is mostly based on components that provide direct and indirect transaction services and yield a return below the 3-month interest rate. Therefore, as Reynard (2007) argues, M2 may be more likely to exhibit a stable relationship with nominal GDP and that rate of interest. In addition, M2 is consistently available for all three currency areas under consideration for the time period 1970Q1 to 2007Q1.

To compute potential output and equilibrium interest rates, we use the HP-trends of actual real GDP and 3-month treasury interest rates in percent. The HP filter is applied to the log-level of real GDP and the interest rate using a standard weighting factor and end-point correction. ${ }^{12}$

Finally, we estimate the $\beta$ coefficients based on simple OLS money demand regressions. Using the log-level of GDP and setting the output elasticity to unity, the results for the full sample period 1970Q1 to 2007Q1 yield estimates of the semi-elasticity of the interest rate of about 0.02 for the US and the euro area, and about 0.06 in the case of Japan.

Note that, by definition, the measure of excess liquidity measure is stationary as long as money demand shocks follow standard assumptions. Equation (4) can be decomposed into deviations

\footnotetext{
${ }^{9}$ That is, we have $m_{t}-p_{t}-y_{t} \equiv v_{t}=c+\beta i_{t}+\varepsilon_{t}$, where the last variable is a well-behaved residual term.

${ }^{10}$ Reynard (2007, Sections 3.1 and 3.2) differs only in notation. He uses $m_{t}^{*}=b+m_{t}-\beta i_{t}^{*}+y_{t}^{*}$ as a nominal equivalent of $m_{t}^{\text {real }}{ }^{*}=-c-\beta i_{t}^{*}+y_{t}^{*}$, with $-b=c$, and, accordingly, writes excess liquidity as $\tilde{m}_{t}=m_{t}^{*}-p_{t}$.

${ }^{11}$ Monetary aggregates are M2- for the US, M2 for the euro area, and M2+CDs for Japan. US M2- corresponds to M2 minus small time deposits, and includes currency, demand and checking deposits, savings accounts, money market deposit accounts, and retail money market funds. Euro area M2 includes currency, overnight deposits, deposits with an agreed maturity up to 2 years, and deposits redeemable at a period of notice up to 3 months. Japanese M2+CDs corresponds to currency, demand deposits, time deposits, fixed savings, installment savings, nonresident yen deposits and foreign currency deposits at banks. Data sources: IFS and national central banks.

${ }^{12}$ As it is now common, we applied the HP filter after extending the raw series using simple AR models to reduce the endpoint bias of the procedure. The HP filters weighting factor has been set to 1,600. Data sources: IFS and national central banks.
} 
of the interest rate from its equilibrium level and real output from potential plus a residual money demand shock, $\varepsilon_{t}$ :

$$
\tilde{m}_{t}=-\beta\left(i_{t}-i_{t}^{*}\right)+\left(y_{t}-y_{t}^{*}\right)+\varepsilon_{t}
$$

As a consequence, $\tilde{m}_{t}$ is stationary as long the $\varepsilon_{\mathrm{t}}$ is. Empirically, we find stationarity over the period 1970Q1 to 2007Q1 for Japan (JP) and the United States (US) at least at the 10 percent level, while the euro area (EA) shows signs of non-stationarity. However, this is mostly driven by recent observations. For instance, we cannot reject stationarity of EA excess liquidity at the 10 percent level for sample periods ending in 2005Q4. ${ }^{13}$ In what follows, we will therefore work with the level of excess liquidity for all three currency areas.

\section{Some STYLIZED FACTS}

Figure 1 shows the excess liquidity measures computed for the United States (US), Japan (JP), and the euro area (EA). For the U.S., except for the period 1980-82 and the second half of 1984, our measure indicates positive excess liquidity from 1970 through 1989, with peaks in 1972, 1977, 1983 and 1986. During the 1990s, U.S. monetary policy turned rather restrictive and only in 2003 excess liquidity became positive up until 2005. In Japan, excess liquidity peaked in 1973 but otherwise showed a modest upward trend until the mid 1980s, possibly reflecting financial deepening. In the run up to the Japanese asset price bubble, excess liquidity surged and hit its highest mark in 1990. Following a sharp contraction during most of the 1990s, liquidity turned positive again in 2003.

Developments in euro area excess liquidity prior to the actual introduction of the euro are somewhat more difficult to interpret. Nevertheless, the quite restrictive stance during the 1990s is likely to reflect a contractionary monetary policy stance in several euro area countries that still had to meet the Maastricht inflation criterion. In 1999, when the euro was introduced, our measure of excess liquidity was negative but liquidity appears to have turned positive in 2001 and has since grown rapidly. It is interesting to note, however, that this widely discussed surge does not look out of the ordinary before late 2003. Until then, EA excess liquidity moved very much in sync with developments in the US and JP. Subsequently, the expansion of US excess liquidity stalled and EA excess liquidity started to eclipse the JP measure.

In general, excess liquidity in all three currency areas show very little comovement in the 1970s and 1980s, but subsequently appear more synchronized. This not entirely surprising given different degrees of financial development across these three regions. Since the early 1990s, however - a period during which conventional measures of financial market integration started to accelerate briskly (IMF, 2005) - excess liquidity shows a surprising degree of comovement across regions, with the exception of the most recent period starting in 2005.

\footnotetext{
${ }^{13}$ Standard unit roots test are performed with Schwartz-criterion determined lag lengths. Available on request.
} 
Figure 1. Excess Liquidity, 1970Q1-2008Q2

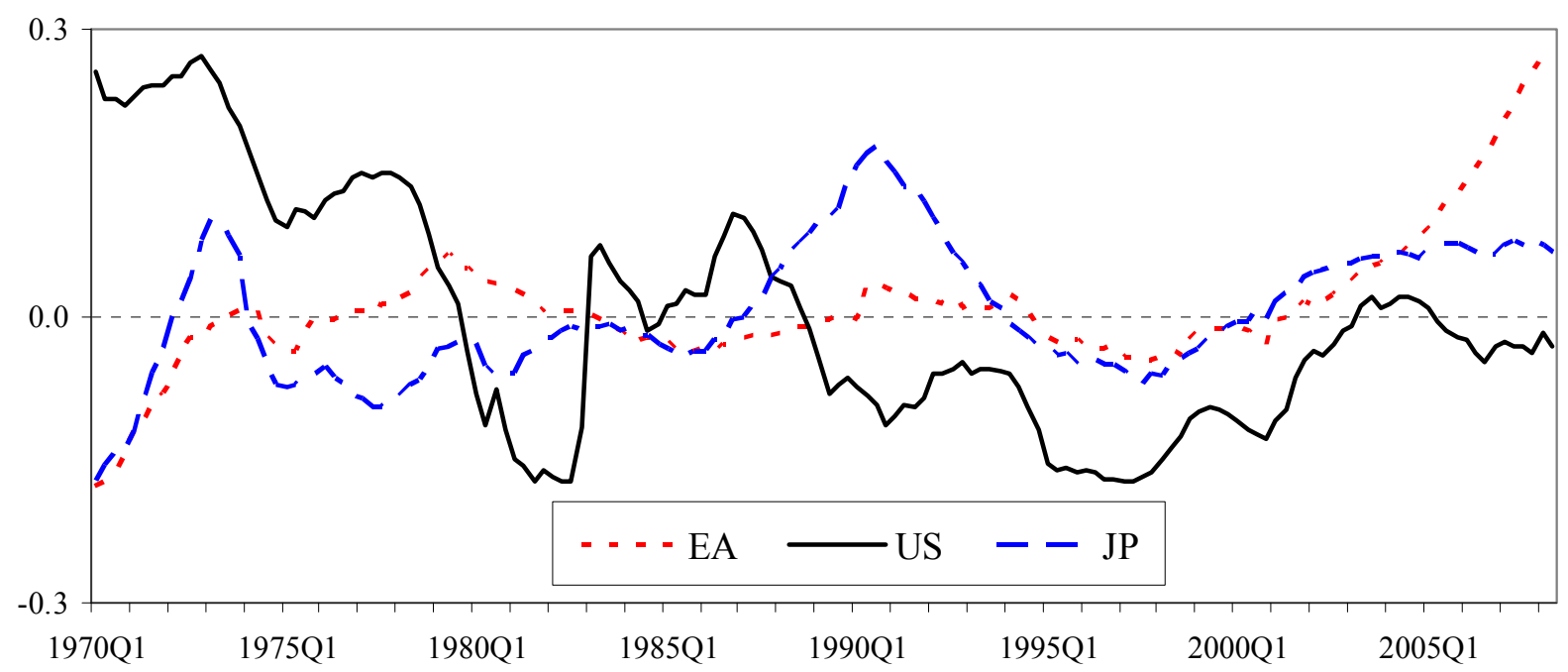

A convenient way to describe the co-movement between times series are dynamic correlation coefficients. Figure 2 presents dynamic correlation coefficients for the EA and the US, the EA and JP, and JP and the US for the full sample period 1971Q1 to 2007Q1 as well as the more recent subperiod 1991Q1 to 2007Q1, allowing for up to 20 leads or lags of either series.

Figure 2. Dynamic Correlation Coefficients of Excess Liquidity
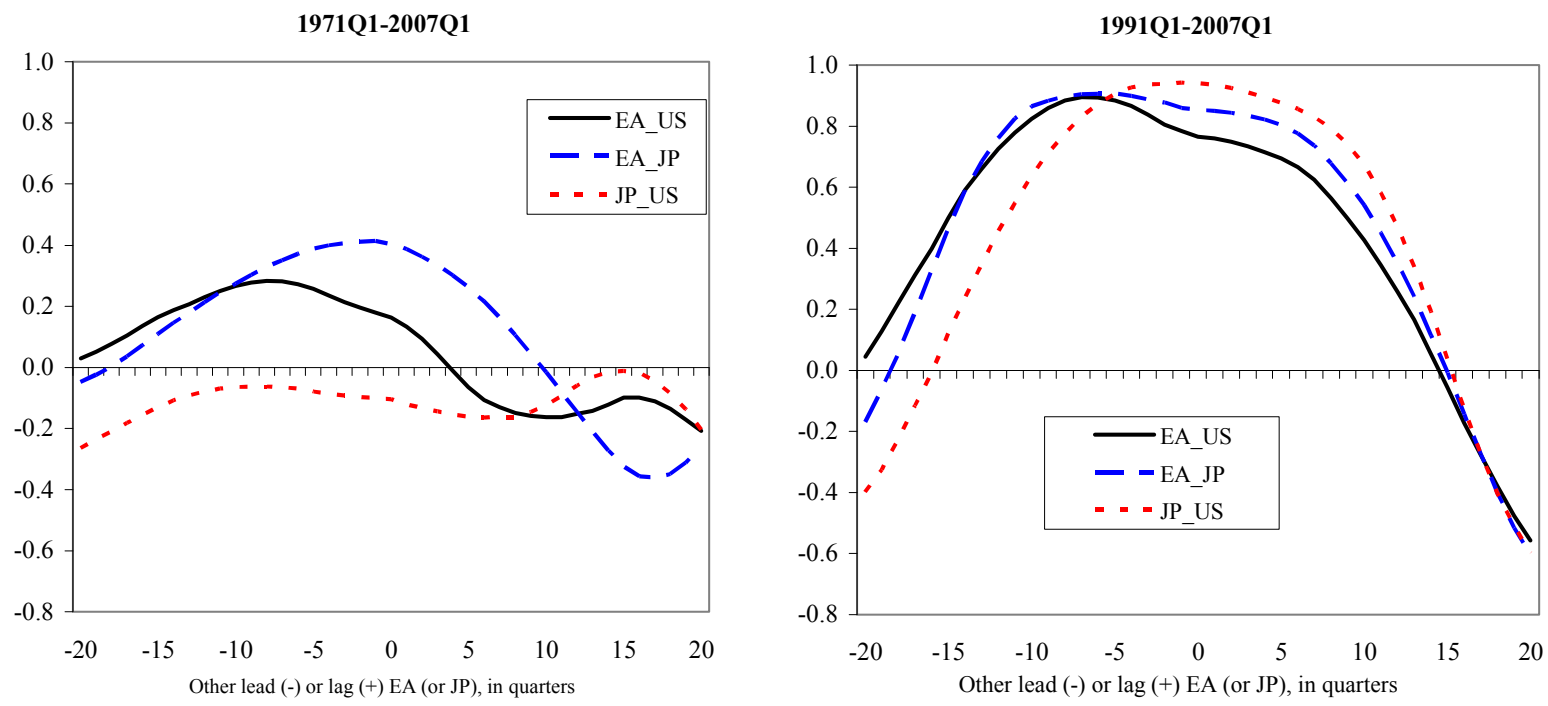

Notes: The coefficients are computed keeping the number of observations at each lead or lag constant, with the data at lag 0 covering the base period 1976Q1 to 2007Q1. For instance, the "EA_US" series at "-10" reports the coefficient of correlation between US excess liquidity during the period 1973Q2 to 2004Q3 with EA liquidity during the base period, while at "10" it reports the correlation between the US excess liquidity during the period 1973Q2 to 2004Q3 with US measure during the base period.

Figure 2 confirms the impression that the correlation of excess liquidity in the three currency areas has increased in recent years. At any lead or lag, the coefficients of correlation barely reach relevant levels when measured over the full sample and, in the case of the US and JP, are even negative throughout (left panel). Since 1991, however, all three liquidity measures are 
highly positively correlated with coefficients of correlation for any regional pair easily exceeding 0.8 (right panel). ${ }^{14}$

A second message conveyed by Figure 2 is that excess liquidity in the US and JP seem to precede EA excess liquidity in the sense that the coefficients of correlation are highest when US and JP liquidity are leading EA liquidity. Both, over the full sample period 1971Q1-2007Q1 and the more recent period 1991Q1-2007Q1, the highest correlation between the US and the EA is observed for the U.S. leading the euro area by about 2 years. But, at about 0.9 compared to about 0.3 , the correlation is much stronger in the more recent period than in the full sample. The results for the EA and JP show a similar pattern, even though maximum correlation tends to be for JP excess liquidity leading EA liquidity only three to six quarters. Compared to these findings, the reverse impact of leading EA excess liquidity on the Japanese and U.S. measures is more limited. While higher EA liquidity tends to be followed by increases in excess liquidity elsewhere, the observed coefficients of correlation are lower, tend to decrease in lead length, and eventually even turn negative.

We find comparable results when describing the dynamic relationship between our measures of excess liquidity in a simple VAR model. In particular, EA excess liquidity tends to react consistently and significantly positive to shocks in U.S. excess liquidity and, to a smaller degree, to shocks in JP liquidity. ${ }^{15}$ The results (not shown) are broadly similar in the full sample period 1971Q1 to 2007Q1 and more recent period 1991Q1 to 2007Q1. ${ }^{16}$

\section{GLOBAL Excess LiQUidity AND EA InFLATION}

For excess liquidity — be it global or regional - to matter from the perspective of monetary policy makers targeting price stability, it must be relevant for inflation. In what follows, we will look at direct within-sample and out-of-sample evidence on this issue.

\footnotetext{
${ }^{14}$ The results at very long lags of EA and JP to the US reflect the prolonged deceleration of US excess liquidity at the beginning of the sample period. Note, however, that the correlation coefficients remain fairly low.

${ }^{15}$ We estimate a VAR for the full sample period 1971Q1 to 2007Q1, including 2 lags (as suggested by information criteria), a constant, and a linear trend. Results are based on a standard Cholesky decomposition with US shocks preceding JP and EA shocks. Results available on request.

${ }^{16}$ In the case of the post-1990 period, the impact of JP shocks on the EA measure are not significant and results tend to be more sensitive to the ordering of the variables.
} 


\section{A. Within Sample}

If the excess liquidity mattered for future inflation as envisaged by the logic of the $\mathrm{P}^{*}$-model, we would expect the various $\tilde{m}$ measures to have a significant positive impact on future inflation in the euro area. Following Reynard (2007), we would anticipate EA excess liquidity to be particularly relevant in this regard.

To investigate this notion, we estimate a simple bivariate autoregressive model explaining future inflation at different horizons by lagged inflation rates and our measures of excess liquidity. ${ }^{17}$ More specifically, we have

$$
\pi_{t+k}=c+\sum_{n=1}^{m} \lambda_{n} \pi_{t-n}+\delta_{i} \tilde{m}_{i, t}+\varepsilon_{t+k}
$$

where $\pi_{t+k}$ is the annualized rate of inflation between the current quarter $t$ and $k$ quarters ahead, $\pi_{t-n}$ is the $n$ period lagged quarterly inflation rate, $\tilde{m}_{i, t}(i=\mathrm{EA}, \mathrm{US}, \mathrm{JP})$ is the current level of excess liquidity in the euro area, the US, or Japan, respectively, and $\varepsilon_{t+k}$ is a residual. The lag length $m$ is set at 4 independent of the forecasting horizon to keep the model tractable.

Table 1: The Impact of EA, US, and JP Excess Liquidity on Future
Inflation

\begin{tabular}{ccccccc}
\hline & \multicolumn{3}{c}{ Sample: 1971Q2 to 2007Q1 } & \multicolumn{3}{c}{ Sample: 1991Q1 to 2007Q1 } \\
\hline $\begin{array}{c}\text { Forecasting } \\
\text { horizon }\end{array}$ & EA & US & JP & EA & US & JP \\
1 & 0.034 & $0.029^{* *}$ & $0.034^{*}$ & 0.008 & 0.013 & $0.031^{*}$ \\
2 & 0.032 & $0.036^{* *}$ & $0.040^{* *}$ & 0.005 & 0.014 & $0.030^{* *}$ \\
4 & 0.040 & $0.051^{* *}$ & $0.048^{* *}$ & 0.014 & $0.021^{* *}$ & $0.038^{* *}$ \\
6 & 0.041 & $0.064^{* *}$ & $0.044^{* *}$ & $0.029^{* *}$ & $0.028^{* *}$ & $0.047^{* *}$ \\
8 & 0.037 & $0.077^{* *}$ & 0.033 & $0.046^{* *}$ & $0.031^{* *}$ & $0.057^{* *}$ \\
10 & 0.017 & $0.088^{* *}$ & 0.019 & $0.056^{* *}$ & $0.033^{* *}$ & $0.063^{* *}$ \\
12 & 0.000 & $0.097^{* *}$ & 0.007 & $0.068^{* *}$ & $0.036^{* *}$ & $0.066^{* *}$ \\
\hline
\end{tabular}

Notes: ${ }^{* *} /{ }^{*}$ indicates significance at least at the $5 / 10$ percent level. The results report the short-run coefficients. Du to the lag structure of the models, the long-run coefficients tend to me higher. Full results available on request. By construction, the exact end date of the samples depends on the forecasting horizon. For instance, it is 2007Q1 for $k=1$ but 2004Q2 for the $k=12$ model.

\footnotetext{
${ }^{17}$ As pointed out by one of our referees, the reduced-from inflation equations could, in principle, be estimated in a two-stage approach, allowing estimation (rather than calibration) of some of the money demand elasticities. While our approach is in line with much of the literature, future research could provide a more detailed empirical framework for the money demand side.
} 
The results presented in Table 1 show excess liquidity to be relevant for inflation, with US liquidity playing a surprisingly prominent role. ${ }^{18}$ The estimated $\delta$ coefficients in the US columns of Table 1 show a significantly positive impact of US excess liquidity on EA inflation at horizons of four or more quarters both in the full sample and the more recent post-1990 period. Quantitatively, a ten percent increase in excess liquidity leads to an increase in future inflation of between 0.3 and 1 percentage point, depending on the horizon. ${ }^{19}$ Japanese excess liquidity plays a somewhat less pronounced role, even though its influence on euro area inflation is present at shorter horizons in the full sample period and there is at least a marginally significant positive impact at all time horizons in the more recent period. In contrast, EA excess liquidity helps explaining EA inflation rates only in the post-1990 sample. While the estimated coefficients are positive for the full sample period, their significance levels only brush the 10 percent level. However, during the more recent period, EA liquidity is significantly related to inflation at long horizons of 6 quarters and higher. The quantitative impact of JP and EA excess liquidity on future euro area inflation is smaller than the US measure but of a similar order of magnitude.

Model misspecification does not seem to be the reason behind the comparatively weak withinsample performance of EA excess liquidity. Consider the argument that the EA measure was driven mostly by idiosyncratic factors while the US measure represented global factors and both were simultaneously relevant for euro area inflation. In this case, the correct model for euro area inflation would include both the EA and the US excess liquidity measure. Empirically, however, this does not seem to be the case: while the explanatory power of the EA measure improves over the full sample period when the US measure is included, it diminishes in the post-1990 period..$^{20}$

\section{B. Out-of Sample}

The within sample evidence discussed so far points to a relationship between euro area inflation and (global) excess liquidity, but does not help in assessing causality. Here, the relevant concept is Granger-causality based on out-of-sample forecasts. Out-of-sample forecasts have been called the "sound and natural approach" to causality testing in multivariate environments (Ashley and others, 1980, p.1149) where traditional within-sample Granger tests are more difficult to implement. Also, out-of sample forecasting is certainly the more relevant approach from an applied perspective, where central banks are interested in whether money contributes to forecasting accuracy for inflation at different horizons.

\footnotetext{
${ }^{18}$ A simple correlation exercise for the liquidity measures and inflation at different horizons yields a similar pattern as Table 1. This suggests that these findings are not driven by the AR part of model (5).

${ }^{19}$ Owing to the lag structure of the forecasting models, the long-run impact tends to be larger. For instance, at about 3.0 percentage points, the long-run impact of a one-time increase of 10 percent in US excess liquidity is about ten times larger than its short-run impact.

${ }^{20}$ This is also true for models including the EA and JP measures. Moreover, we results similar to Table 1 in twostage models, which, at stage one, explain EA excess liquidity by various lags of US and JP liquidity and use, at stage two, the residuals to explain euro area inflation jointly with current US excess liquidity. Additional results on request.
} 
To answer the question whether the various excess liquidity aggregates Granger-cause inflation, we estimate model (5) for a baseline or training period 1971Q2 to 1990Q4 (79 observations) and make one-period-ahead (pseudo) out-of-sample forecasts for future inflation at all $k=1, . .12$ time horizons. This exercise is then repeated for an extended baseline period including one additional quarter and so on, yielding, depending on the time horizon, between 54 and 64 forecasts for future EA inflation in the forecasting period 1991Q1 to 2007Q1. These forecasts can then be compared with actual observations.

Figure 3 depicts the Root Mean Square Error (RMSE) for four different models of EA inflation. The first model, "AR(4)", which serves as benchmark, uses only the four lagged quarter-onquarter inflation rates plus a constant to predict future inflation. The question is, whether the models including, in addition, measures of EA, US, or JP excess liquidity produce RMSEs higher or lower than the benchmark model. If a model including a particular measure of excess liquidity produced a lower RMSE at some forecasting horizon, we would conclude that this measure Granger-causes inflation.

Figure 3. RMSEs for Alternative Models of Euro Area Inflation for the Forecasting Period 1991Q1 to 2007Q1

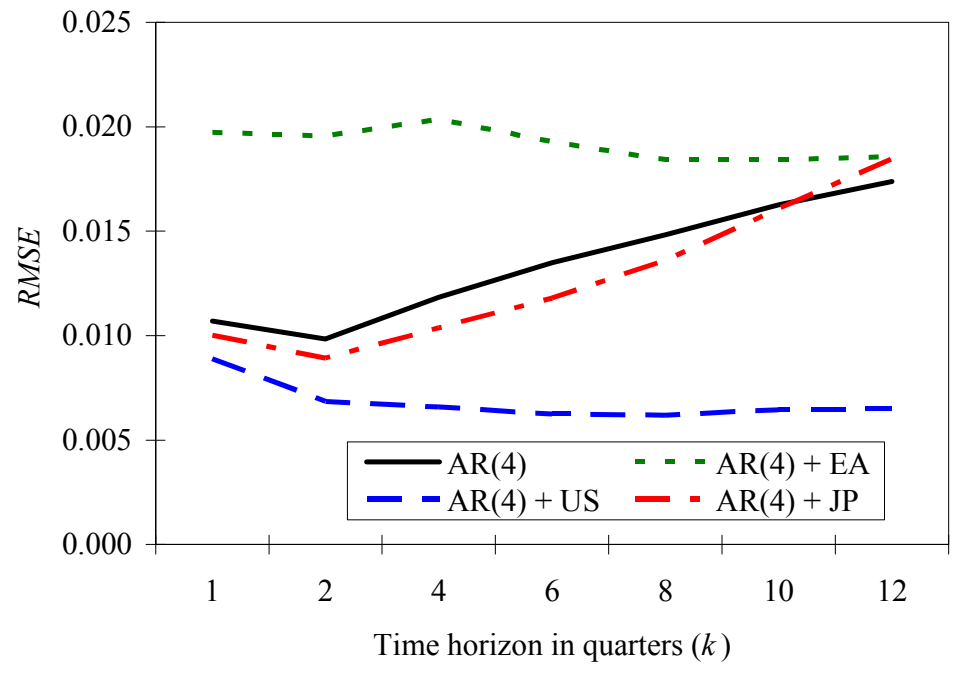

Notes: Reported are standard Root Mean Squared Errors (RMSEs) from four forecasting models at $k=1, \ldots 12$ quarter horizons. A lower RMSE indicates better outof-sample forecasting performance. See text for details.

Figure 3 suggests that, in particular, US excess liquidity may be an important — or Grangercausal-factor in explaining the time path of future EA inflation out-of-sample. The forecasting model employing US liquidity produces RMSEs that are lower than the benchmark model at all time horizons, with particular substantial gains in forecasting accuracy for inflation one year or longer in the future. The average gain in forecasting inflation over the AR(4) model increases from about 0.2 percentage points one quarter ahead to about 0.7 and 1 percentage point six and twelve quarters ahead, respectively.

Compared to the US measure, the performance of the JP and, in particular, the EA measures are less impressive. Strictly interpreted, JP excess liquidity is Granger-causal for EA inflation, too. However, compared to the model including US liquidity, the difference between the JP excess 
liquidity model and the simple AR(4) model remains small and turns negative at very long horizons. In contrast, adding EA excess liquidity to the benchmark model does not improve forecasting accuracy at any horizon.

A combination of factors could be behind these results. From a quantity-theoretic perspective, a surge in global liquidity could mean higher future euro area rates of inflation if it was accompanied by an increase in EA excess liquidity, which, in turn, could impact inflation along the lines of the $\mathrm{P}^{*}$ model. Another explanation is that euro area inflation is directly influenced by global excess liquidity, for which developments in the U.S. seem to be a good proxy. As the ECB (2008) points out, global liquidity conditions can influence asset prices and, as a consequence, lead to the changes in financial flows and wealth effects at the domestic side. A related impact channel could be commodity prices and the terms of trade. Lastly, a possible indirect consequence of financial globalization along these lines discussed by Mishkin (2008, p.9) is a reduced "scope" for individual central banks to control domestic monetary conditions, perhaps because bank lending is less sensitive to changes in monetary policy conditions in times of global excess liquidity. We will return to this issue below.

At a more technical level, US (or global) excess liquidity may be more relevant for euro area inflation than EA excess liquidity because the former moves less idiosyncratically than the latter. ${ }^{21}$ The within-sample fit of the EA-based model is comparatively weak, and the explosive behavior of EA excess liquidity toward the end of the forecasting period tends to increase the RMSE. While, as discussed, excess liquidity in the US, JP, and the EA moved more or less in sync during most of the 1990s and early 2000s, the increase in the EA measure after 2003 is exceptional and — or so the results suggest - hard to square with the actual time path of inflation at any horizon. ${ }^{22}$

The basic message of Figure 3, that global liquidity developments help forecast euro are inflation, is reasonably robust. As a rule, the liquidity based models perform slightly less convincingly when the training period is shortened. However, the US excess liquidity measure generally tends to do better than the EA and the JP measure and often beats the benchmark model. For instance, choosing 1985Q1 to 1995Q4 as a base period, which allows the model to adjust to the lower inflationary environment of the "great moderation" period, and forecasting into the run-up and implementation period of the European Economic and Monetary Union (EMU), 1996Q1 to 2007Q1, shows that the model including US excess liquidity produces lower RMSEs than the benchmark at horizons of 6 quarters and longer (see Figure A1 in the Appendix).

\footnotetext{
${ }^{21}$ Of course, a richer econometric setup than the simple one employed here might help all liquidity-based models, including the EA-based one, to contribute more to the forecasting accuracy of AR(4) model. See, for instance, Hofmann (2006) and Assenmacher-Wesche and Gerlach (2007) for recent results pointing in that direction. Note, however, that a better performance compared to the AR(4) benchmark would not necessarily mean better performance relative to, for instance, the US model. In addition, as Berger and Österholm (2008) warn that the contribution of monetary aggregates to forecasting euro area inflation has decreased since the $1980 \mathrm{~s}$, it would seem that - if anything - the above results (based on a very long sample period) are biased in favor of finding a relatively large role of EA excess liquidity.

${ }^{22}$ This point is broadly related to the findings of D'Agostino and Surico (2007), who report for U.S. that a (different) measure of global liquidity improves the forecasting of US inflation.
} 


\section{A Glimpse at the Link between Global Liquidity and Monetary Policy EFFECTIVENESS}

One channel providing a link from global excess liquidity to euro area inflation is the possibility of reduced effectiveness of monetary policy in the presence of excess global liquidity. For instance, in a credit channel framework ample liquidity might help insulate banks from changes in domestic monetary policy conditions, while policy could be more effective when liquidity is scarce (see e.g. Kashyap and Stein (2000), Ehrmann and others (2003), and Saxegaard (2006)). As a result, euro area economic conditions may be more likely to be driven by other factors, including for instance direct effects of changing global liquidity conditions through changes in global asset or commodity prices (see previous section).

A simple way to shed some light on this issue is a standard VAR for the EA. The model can be used to answer the question, whether the impact of an unanticipated shock to interest rates impacts the economy differently under different regimes of global (or US) excess liquidity. Broadly following Peersman and Smets (2001) and Sousa and Zaghini (2004), we employ a VAR for the EA of the form

$$
\mathbf{A}(L) \mathbf{Y}_{t}=\mathbf{u}_{t}
$$

where $\mathbf{Y}_{t}=\left(y_{t} p_{t} m_{t} i_{t} s_{t}\right)^{\prime}$ is a $(5 \times 1)$ vector of observations at time $t$, with $y_{t}$ representing real GDP, $p_{t}$ the consumer price index, $m_{t}$ the monetary aggregate $\mathrm{M} 2, i_{t}$ three months interest rates, and $s_{t}$ the real effective exchange rate. All variables except the interest rate are in log-levels and deseasonalized. The $(5 \times 1)$ vector of disturbances $\mathbf{u}_{t}$ follows the usual assumptions, that is, we assume $\mathrm{E}\left(\mathbf{u}_{t}\right)=\mathbf{0}, \mathrm{E}\left(\mathbf{u}_{t} \mathbf{u}_{t}^{\prime}\right)=\Sigma, \mathrm{E}\left(\mathbf{u}_{t} \mathbf{u}_{t^{\prime}}^{\prime}\right)=\mathbf{0} \forall t \neq t^{\prime} . \mathbf{A}(L)$ is a matrix polynomial in the lag operator $L$, with the lag length set to $4 .{ }^{23}$

In addition to $\mathbf{Y}_{t}$, the model also includes a set of exogenous variables, including a constant and a linear time trend, as well as the oil price in US\$, an index of international non-fuel commodity prices, and the US three month interest rate, price level, and real GDP. The last group of variables is often considered helpful to properly identify interest-rate based monetary policy shocks without counterintuitive reactions of the price level (the so-called prize puzzle). All exogenous variables with the exception of the interest rate are in deseasonalized log-levels.

\footnotetext{
${ }^{23}$ The (uniform) lag length is compatible with standard information criteria. Note that more extensive lag structures quickly exhaust degrees of freedom.
} 
Figure 4. Results from an Unconditional VAR for the Euro Area 1991Q1 to 2007Q1
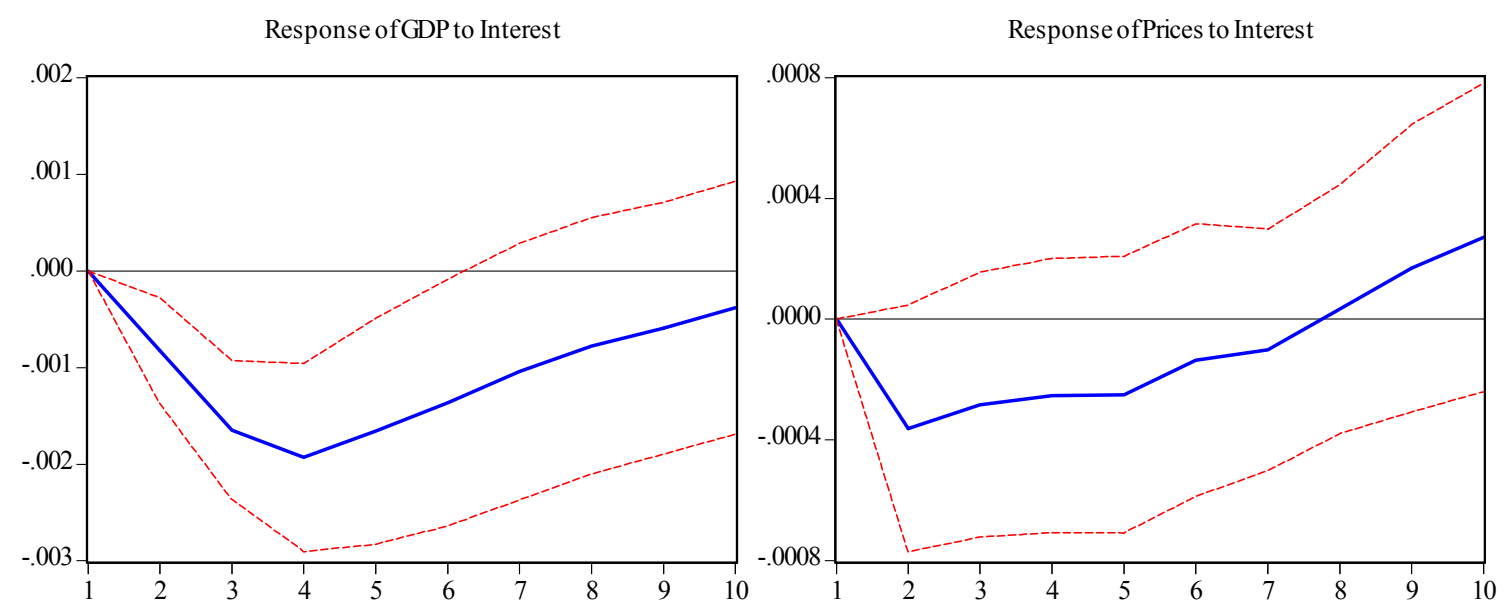

Notes: Shown are the impulse responses to a Cholesky one standard deviation shock to interest rates on real GDP and the consumer price index with their respective 2-standard-error bands. See text for details.

In line with the forecasting exercise in the previous section, we estimate model (6) for the period 1991Q1 to 2007Q1, which leaves us (after data restrictions) with 62 quarterly observations. Figure 4 displays the Cholesky impulse responses of real GDP and the price level to a one-standard-deviation shock in interest rates with the relevant two-standard-error bands. The ordering follows the definition of $\mathbf{Y}_{t}$, and is based on the notion that short-term interest rates follow a Taylor-type rule conditional on observed real and nominal variables, while the exchange rate reacts to interest rates. ${ }^{24}$ The results suggest that real GDP declines significantly after the interest rate hike, with the maximum impact reached after about 4 quarters. The impact of the price level, while pointing in the right (negative) direction, is not significantly negative, perhaps owing to the shortness of the sample. The results are broadly in line with what Peersman and Smets (2001) and Sousa and Zaghini (2004) report for the EA. The question is, however, whether the interest rate channel present in Figure 4 exists independently on the global excess liquidity regime.

To answer this question, we first define a US, JP, or EA excess liquidity regime as a state of the world in which the particular excess liquidity measure is positive. In contrast, regimes with no excess liquidity are states of the world where the respective conditions for an excess liquidity regime are not fulfilled. The latter regime includes all periods with non-negative (i.e. zero or positive) excess liquidity. Turning to the data, during the 1991Q1 to 2007Q1 sample, an US excess liquidity regime is in place for the eight quarters between 2003Q2 and 2005Q1. There are 38 quarters during which either the EA or JP register excess liquidity regimes (compare Figure 1). Finally, we also defined a global excess liquidity regime as a state of the world where

\footnotetext{
24 The setup is standard and, as any VAR-based exercise, assumes that interest rates are set contemporaneously and not forward-looking, for instance because the central bank follows an optimal simple policy rule. The Cholesky procedure is adjusted for degrees of freedom. In general, we get similar results for alternative orderings of the variables - for instance, if we assume that the exchange rate precedes interest rates. See e.g. Favero and Giavazzi (2008) for a more in-depth discussion of the role of international financial conditions for the euro area.
} 
both the US and the JP excess liquidity measure are positive. As it turns out, however, the global and the US excess regime are identical. ${ }^{25}$

In a second step, we re-estimate the VAR model (6) conditioning the interest rate related components of $\mathbf{A}(L)$ on the presence or absence of the various excess liquidity regimes. ${ }^{26}$ In principle, if global liquidity has no repercussions for the effectiveness of the euro area interest rate channel, we would expect the impulse responses shown in Figure 4 to be the same under the excessive and the non-excessive global liquidity regime. If, however, monetary policy becomes largely ineffective in the presence of global excessive liquidity, the impulse responses of inflation and output to an interest rate shock might differ.

The results suggest that in particular US excess liquidity regimes may matter for policy effectiveness in the euro area. In the case of the EA and JP, we do not find the expected differences in the workings of the interest rate channel. ${ }^{27}$ For instance, for the EA, there is a negative impact of interest rates shocks both under the excess and the no excess liquidity regime; and in the case of JP, there is a significant negative reaction of output only under the excess liquidity regime. There is, however, some evidence that a regime of excess liquidity in the US (and, thus, also global excess liquidity regimes) may impede the interest channel. Figure 5 presents the impulse responses of real GDP and the consumer price index to interest rate shocks under the no excess liquidity regime (first column) and in the excess liquidity regime (second column) in this case.

Comparing the reaction of real GDP to an interest rate shock across regimes (top row), we find a significant decline in real activity only in the absence of global excess liquidity. In the presence of excess liquidity, however, the reaction of output is minimal and not different form zero. In short, a "normal" reaction of real activity to interest rate shocks seems more likely in the absence of US or global excess liquidity. Similarly, there is the expected negative significant reaction of prices under the no excess liquidity regime, while the price level hardly moves under the excess liquidity regime.

\footnotetext{
${ }^{25}$ This is because the JP excess liquidity measure is positive whenever the US measure is.

${ }^{26}$ This is done by substituting $i_{t}$ in $\mathbf{Y}_{t}$ by two variables, $D_{t} i_{t}$ and $\left(1-D_{t}\right) i_{t}$, where $D_{t}$ is a dummy variable that is 0 in the no excess liquidity regime and 1 in the excess liquidity regime. To limit complications for the residuals, we also add $D_{t}$ and its first difference $\mathrm{d}\left(D_{t}\right)$ to our set of exogenous variables. Where the data allowed, following Berger and Woitek (2005), we also conditioned the full $\mathbf{A}(L)$ matrix on the global excess liquidity regime by estimating $\mathbf{A}_{1}(L) \mathbf{y}_{t}=\mathbf{u}_{1 t}$ if $D_{\mathrm{t}}=1$ and $\mathbf{A}_{2}(L) \mathbf{y}_{t}=\mathbf{u}_{2 t}$ otherwise, with $L$ being the same in both models. The results are generally comparable with what we report above.

${ }^{27}$ Results not shown, available on request.
} 


\section{Figure 5. Results from a VAR for the Euro Area 1991Q1 to 2007Q1 Conditional on the US Excess Liquidity Regime}

No Excess Liquidity: Response of GDP to Interest

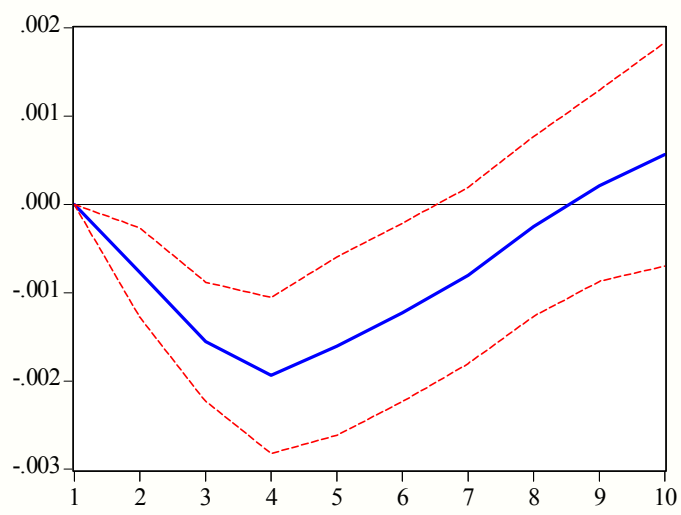

No Excess Liquidity: Response of Prices to Interest

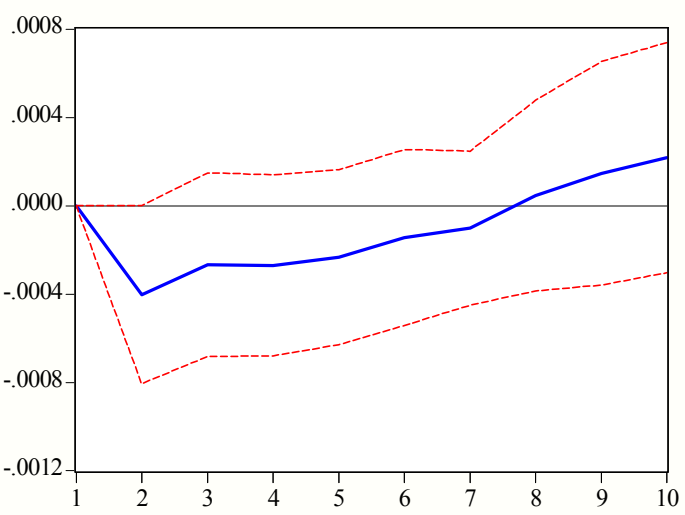

Excess Liquidity: Response of GDP to Interest

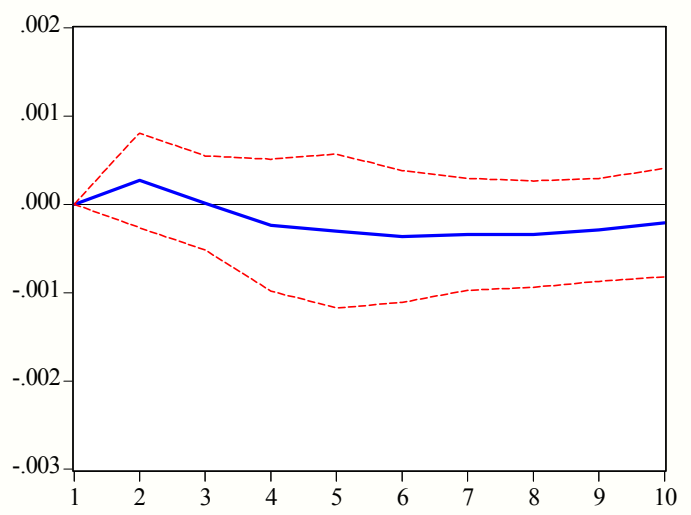

Excess Liquidity: Response of Prices to Interest

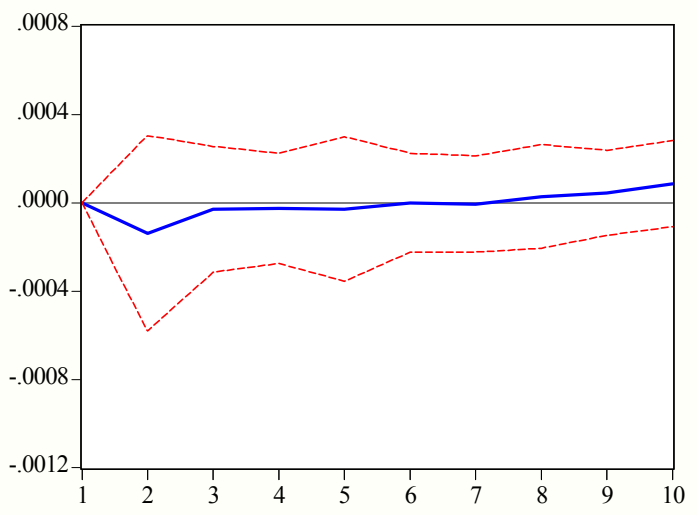

Notes: Shown are the impulse responses to a Cholesky one standard deviation shock to interest rates on real GDP and the consumer price index with their respective 2-standard-error bands conditional on the US excess liquidity regime. See text for details.

The results are robust to a number of modifications - but they clearly need to be interpreted with caution. In terms of robustness, we find very similar results to Figure 5 when estimating the model either in first or annual differences. ${ }^{28}$ This is also true for somewhat more generous definitions of global excess liquidity that capture the upward movement of US liquidity setting in around $2001 .{ }^{29}$ However, it is also important to keep in mind that the excess liquidity regime covers a relatively short time span and, empirically, coincides with the period during which

\footnotetext{
${ }^{28}$ Additional results available on request.

${ }^{29}$ Changing the definition of the US excess liquidity regime, for instance, by picking a lower constant $c$ in equation (4), which extends the excess regime to include more of the post-2001 period, does lead to similar results.
} 
ECB policy rates moved little and certain structural changes such as the euro changeover occurred. ${ }^{30}$

\section{Conclusion}

We find that excess liquidity (that is, levels of M2 in excess of money demand implied by longer-run interest rates and output developments) in the euro area shows considerable comovement with excess liquidity in the U.S. and Japan, with the latter often leading euro area developments. Both findings are particularly strong for the U.S. and during the post-1990 period.

Moreover, U.S. excess liquidity is consistently having a positive impact on future euro area inflation up to 12 quarters ahead. In particular, U.S. excess liquidity has a positive and significant influence on future euro area inflation within sample and is Granger-causal (in the sense of positively influencing forecasting accuracy) for euro area inflation out-of-sample. This contrasts with an only limited and often even negative marginal contribution of Japanese and euro area excess liquidity to the within- and out-of-sample explanation of euro inflation. This finding suggests that global liquidity conditions, proxied by U.S. liquidity, matter for euro area inflation more than domestic liquidity conditions.

In technical terms, our results caution against a mechanistic interpretation of the link between liquidity developments and euro area inflation. Clearly, liquidity seems to matter for euro area inflation - but the link is not a simple one. For instance, correcting for long-run output and interest rate effects (or alternative means) to identify excess liquidity seems essential. Moreover, it is global rather than euro area excess liquidity that is most strongly related to future rates of euro area inflation. One way to look at the latter finding is that interpreting regional liquidity developments in light of global liquidity movements may help in identifying idiosyncratic developments that are less likely to influence inflation.

Another question is what is driving these results in economic terms. One explanation could be indirect effects working through a reaction of euro area liquidity to global developments. Also direct effects could be at play, operating through international asset and commodity prices. Another explanation is that monetary policy might be less effective under a regime of global excess liquidity, for instance because credit channel mechanisms tend to become weaker in times of ample liquidity. Interestingly, there is some evidence that global liquidity regimes impact the monetary transmission mechanism in the euro area. The finding invites further discussion, not least because of data limitations. However, if correct, it would suggest that the documented influence of global liquidity on euro area inflation could, at least in part, be due to changes in the ability of monetary policy to lean against the tides in international financial conditions.

\footnotetext{
${ }^{30}$ The ECB lowered the rate on its marginal lending facility from 3.75 to 3.5 percent on 7 March 2005 and to 3 percent on 6 June 2005. The rate then remained constant until the end of 2005. Note, however, that the VAR models discussed above are based on 3 month interest rates, which offer somewhat greater variance.
} 
What does all this tells us in light of more recent developments? Since the onset of the financial turmoil in August 2007, our measure of U.S. excess liquidity has remained subdued, despite the significant reduction in U.S. policy rates and other more direct liquidity-enhancing actions.

Against this background, our results would suggest that inflationary pressures in the euro area, stemming for global liquidity developments should remain contained. That said, the global nature of the financial crisis has shown the potential to force the hands of central banks and limit their room of maneuver over and beyond the development of global liquidity stocks and flows. This, too, supports the general notion that financial globalization is an interesting subject for students of monetary policy. 


\section{REFERENCES}

Andrés, Javier David Lopez-Salido, and Edward Nelson, 2007, "Money and the Natural Rate of Interest: Structural Estimates for the UK, the US and the Euro Area," Research Division Federal Reserve Bank of St. Louis Working Paper Series, 2007-005A.

Ashley, R., Clive W. J. Granger and R. Schmalensee, 1980, "Advertising and Aggregate Consumption: An Analysis of Causality,” Econometrica, Vol. 48, pp. 1149-1167.

Assenmacher-Wesche, Katrin and Stefan Gerlach, 2007, "Understanding the Link between Money Growth and Inflation in the Euro Area," in: David Cobham (ed.), The Travails of the Eurozone (Palgrave: Basingstoke), pp. 10-39.

Berger, Helge and Ulrich Woitek, 2005, Does Conservatism Matter? A Time Series Approach to Central Banking, Economic Journal, Vol. 115 (July), pp. 745-766.

Berger, Helge and Pär Österholm, 2008, "Does Money Growth Cause Inflation in the Euro Area? Evidence from Out-of-Sample Forecasts Using Bayesian VARs," IMF Working Paper No. 08/53 (Washington: International Monetary Fund).

Bini-Smaghi, L., 2007, Speech 11 October 2007, available online under: http://www.ecb.int/press/key/date/2007/html/index.en.html.

D’Agostino, Antonello and Paolo Surico, 2007, "Forecasting Inflation with Global Liquidity," Manuscript, (no month).

Deutsche Bundesbank, 2005, "The Relationship Between Money and Prices", Monthly Report, January, pp. 13-24.

Ehrmann, Michael, Leonardo Gambacorta, Jorge Martínez-Pagés, Patrick Sevestre, and Andreas Worms (2003), "Financial Systems and the Role of Bank in Monetary Transmission in the Euro Area," in: Ignazio Angeloni, Anil Kashyap, and Benoît Mojon (eds.), Monetary Transmission in the Euro Area: A Study by the Eurosystem Monetary Transmission Network, (Cambridge: Cambridge University Press) pp. 235-269.

European Central Bank (ECB), 2008, “The External Dimension of Monetary Policy,” Monthly Bulletin, August, pp. 71-84.

Favero, Carlo and Francesco Giavazzi, 2008, "Should the Euro Area be Run as a Closed Economy?" Amercian Economic Review: Papers and Proceedings, Vol. 98:2, pp. 138145.

Fischer, Björn, Michele Lenza, Huw Pill, and Lucrezia Reichlin (2008), "Money and Monetary Policy: The ECB Experience 1999-2006," in: Andreas Beyer and Lucrezia Reichlin (eds.), The Role of Money-Money and Monetary Policy in the Twenty-First Century, Proceedings of the Forth ECB Central Banking Conference 9-10 November 2006, (Frankfurt: ECB), pp. 102-175. 
Gerlach, Stefan and Lars Svensson, 2003, "Money and Inflation in the Euro Area: A Case for Monetary Indicators?” Journal of Monetary Economics, Vol. 50(8), pp. 1649-72.

Hallman, Jeffrey, Richard Porter, and David Small, 1991, "Is the Price Level Tied to the M2 Monetary Aggregate in the Long Run?" The American Economic Review, Vol. 81(4), pp. 841-58.

Hofmann, Boris, 2006, “Do Monetary Indicators (Still) Predict Euro Area Inflation?” Deutsche Bundesbank Discussion Paper 18/2006.

International Monetary Fund (IMF), 2005, Globalization and External Imbalances (Chapter III), World Economic Outlook, April, pp. 109-156.

—, 2007, What Is Global Liquidity (Box 1.4), World Economic Outlook, October, 34-37.

Masuch, Klaus, Huw Pill, and Caroline Willeke, 2001, "Framework and Tools of Monetary Analysis," in: Hans-Joachim Klöckers and Caroline Willeke, Monetary Analysis: Tools and Applications, (European Central Bank: Frankfurt), pp. 117-44.

Mishkin, Frederic, 2008, Globalization, Macroeconomic Performance, and Monetary Policy, NBER Working Paper 13948.

Nelson, Edward, 2003, "The Future of Monetary Aggregates in Monetary Policy Analysis," Journal of Monetary Economics, Vol. 50(5), pp. 1029-59.

Neumann, Manfred, 1997, "Monetary Targeting in Germany," in: Iwao Kuroda (ed.), Towards More Effective Monetary Policy, (London: Macmillan), pp. 176-210.

Orphanides, Athanasios and Richard Porter, 2000, "P* Revisited: Money-Based Inflation Forecasts with a Changing Equilibrium Velocity," Journal of Economics and Business, Vol. 52(1/2), pp. 87-100.

Kashyap, Anil and Jeremy Stein, 2000, "What Do a Million Banks Have to Say About the Transmission of Monetary Policy?” American Economic Review, Vol. 90(3), pp. 40728.

Peersman, Gert and Frank Smets, 2001, "The Monetary Transmission Mechanism in the Euro Area: More Evidence from VAR Analysis," ECB Working Paper, 91, December.

Reynard, Samuel, 2007, "Maintaining Low Inflation, Money, Interest Rates, and Policy Stance," Journal of Monetary Economics, Vol. 54(5), pp. 1441-71.

Rüffer, Rasmus and Livio Stracca, 2006, "What is Global Excess Liquidity, And Does It Matter?” ECB Working Paper, 696. 
Saxegaard, Magnus, 2006, "Excess Liquidity and Effectiveness of Monetary Policy: Evidence from Sub-Saharan Africa," IMF Working Paper No. 06/115 (Washington: International Monetary Fund).

Sousa, João and Andrea Zaghini, 2004, "Monetary Policy Shocks in the Euro Area and Global Liquidity Spillovers," ECB Working Paper, 309, February.

Svensson, Lars, 2000, "Does the P* Model Provide Any Rationale for Monetary Targeting?" German Economic Review, Vol. 1, pp. 69-81.

Tödter, Karl-Heinz and Hans-Eggert Reimers, 1997, "P-star as a Link Between Money and Prices in Germany," Weltwirtschaftliches Archiv, Vol. 130, pp. 273-89.

Von Hagen, Jürgen, 1995, "Inflation an Monetary Targeting in Germany,” in: Leonardo Leiderman and Lars Svensson (eds.), Inflation Targets, (CEPR: London), 107-21.

Warsh, K., 2007, Speech 5 March 2007, available online under: http://www.federalreserve.gov/newsevents/speech/2007speech.htm

Woodford, Michael, 2003, Interest and Prices: Foundations of a Theory of Monetary Policy, (Princeton University Press: Princeton).

—, 2007 , "How Important is Money in the Conduct of Monetary Policy," NBER Working Paper, 13325. 


\section{Appendix}

Figure A1. RMSEs for Alternative Models of Euro Area Inflation for the Base Period 1985Q1 to 1995Q4 and the Forecasting Period 1996Q1 to 2007Q1

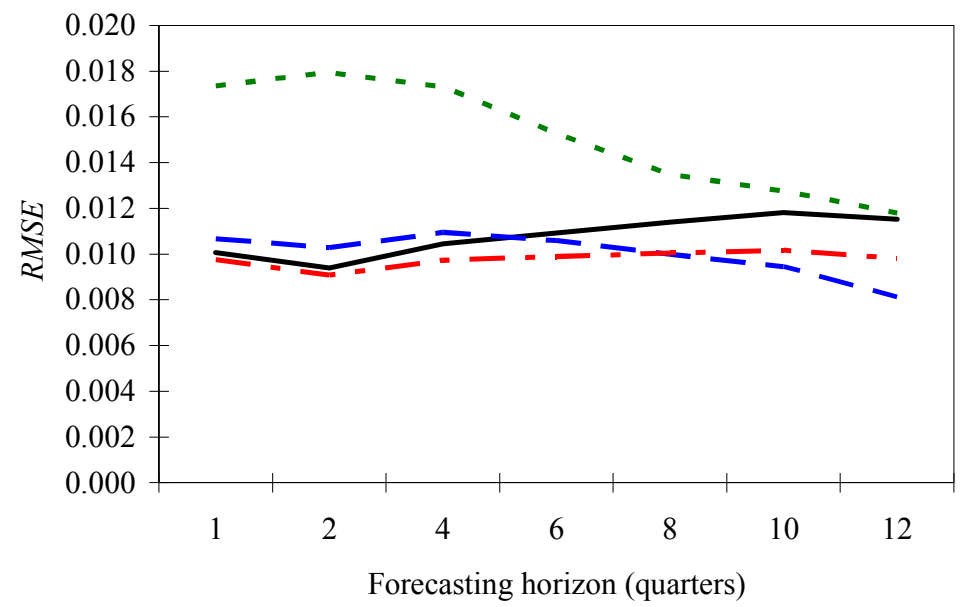

$$
\begin{array}{|ll|}
\hline-\mathrm{AR}(4) & =-\mathrm{AR}(4)+\mathrm{EA} \\
--\mathrm{AR}(4)+\mathrm{US} & --\mathrm{AR}(4)+\mathrm{JP} \\
\hline
\end{array}
$$

Notes: Reported are standard Root Mean Squared Errors (RMSEs) from four forecasting models at $k=1, \ldots 12$ quarter horizons. A lower RMSE indicates better out-of-sample forecasting performance. See main text for details. 